\title{
La búsqueda de la identidad en las historias de vida
}

André Gattaz UNIVERSIDAD DE SAO PAULO

\author{
Destaca la importancia en la historia oral de conocer e \\ interpretar los signos de la identidad presentes en la historia \\ de vida, percibir su interrelación con la trayectoria vivida por \\ el narrador y la forma en que se estructura su propia \\ narrativa en un complejo ejercicio dialéctico.
}

"Se imprime en la narrativa la
marca del narrador como la mano
del alfarero en la arcilla de la
vasija."
Walter Benjamin

E

n la historia de vida la identidad del entrevistado se manifiesta de varias formas, de las más explícitas a las más imperceptibles, con mayor o menor conciencia. Por otro lado, la identidad del narrador está íntimamente asociada a su trayectoria de vida en una vía de dos direcciones. El vector resultante de esas dos "fuerzas", trayectoria de vida e identidad, actúa en el momento de la elaboración de la autobiografía, haciendo que ésta sea claramente un reflejo de ambas más que una simple consecuencia, lo que me parece una hipótesis reduccionista.

Como un reflejo activo, la historia de vida no debe ser considerada puramente como una consecuencia de la identidad, y ésta de la trayectoria, sino también como una moldeadora de la identidad y de la trayectoria de vida. Ésta, si por un lado existió de hecho y tuvo una y solamente una, orientación factual, por otro se construye nuevamente en el momento de la entrevista, muchas veces revestida de im- 
portancia para la reelaboración o ree$x a m$ de un self.

Para mejor develar la documentación oral recogida, el oralista debe buscar, conocer e interpretar los signos de la identidad presentes en la historia de vida, percibiendo su interrelación con la trayectoria vivida por el narrador y la forma en que se estructura su propia narrativa, en un complejo ejercicio dialéctico.

La historia de vida, que en muchos puntos es semejante a la autobiografia espontánea, trae consigo una serie de características que no se manifiestan en otro tipo de documentos históricos, especialmente aquellos que en su origen tuvieron oscurecida o neutralizada la personalidad de quien lo compuso. En la narrativa autobiográfica, como observó Georges Gusdorf,

la unidad de comportamiento y de actitudes no procede del exterior: es cierto que los hechos influyen, a veces determinan y siempre delimitan, pero los temas esenciales, los esquemas estructurales que se imponen al material exterior, son los elementos constituyentes de la personalidad.

Los aspectos individuales en la historia de vida son exacerbados, mientras los movimientos generales de la historia asumen casi siempre un plano secundario, y eso hace que nuestro abordaje de estos testimonios difiera del que daríamos a una serie estadística o a un documento gubernamental. De esta forma se distingue también la historia oral de vida, preocupada por la experiencia subjetiva, de la historia oral temática, volcada hacia el hecho objetivo y la reconstrucción de un pa- sado ignorado. En la historia de vida, la verdad de los hechos se subordina a la verdad del hombre, pues es el hombre lo que está en cuestión.

Otras características de la historia de vida tienen que ver con el momento de su creación. La grabación de la entrevista entre el oralista y su colaborador y no informante, cristaliza en una manifestación histórica. Su análisis, así, debe considerarla como una forma expresiva determinada por el espacio y por el tiempo, que no refleja tanto el sentido que el narrador tuvo de los hechos en el pasado, sino el que le otorga en el momento de la entrevista y no, por cierto, de forma inocente y sin consecuencias, como pretenden algunos estudiosos.

Para Daphne Patai, autora de un importante libro sobre las mujeres brasileñas,

el acto de contar una historia de vida implica una racionalización del pasado como es proyectado y lleva a un presente inevitable. Y, de hecho, una versión particular de la historia de vida de alguien se puede tornar un componente esencial en su sentido de identidad en un momento dado. Del enorme repertorio de memorias y respuestas posibles evocadas por la situación de entrevista, la persona entrevistada selecciona y organiza ciertos temas, incidentes y recuerdos, que son entonces comunicados en una forma particular.

De esta forma, cuando alguien cuenta su propia historia, busca reunir los elementos dispersos de su vida personal y agruparlos en un esquema de conjunto, intentando conseguir una expresión coherente y total de su destino. Esta tarea exige que el hombre se 
sitúe a una cierta distancia de sí mismo, a fin de reconstruirse en su unidad y en su identidad a través del tiempo. La narrativa autobiográfica así nos trae el testimonio de un hombre sobre sí mismo, el debate de una existencia que dialoga con ella misma en la búsqueda de su fidelidad más íntima.

Para el narrador no es fácil este volver sobre su vida. El espacio interior es tenebroso por excelencia. La sociología, la psicología y el psicoanálisis revelaron la significación compleja y angustiosa que reviste el encuentro del hombre con su imagen. "La imagen es un doble de mi ser, pero más frágil y vulnerable, revestida de un carácter sagrado que la torna al mismo tiempo fascinante y terrible."

Para domesticar esta imagen, el entrevistado tiene la necesidad de apoyarse sobre ejes narrativos, que orientan la construcción de una historia coherente sobre la multiplicidad de imagen y conceptos guardados en el estante infinito de la memoria. Por eso las características personales que el sujeto quiere hacer constar como aquellas que mejor representan su vida y su personalidad, aparecen como el hilo conductor de la narrativa, definiendo su tono vital y sus eventos clave. Estos ejes temáticos determinan la interpretación teleológica que el narrador hace de la vida en el momento de la entrevista.

La preponderancia de un hilo conductor, sin embargo, no está subordinada solamente a la creatividad narrativa del entrevistado, sino a su propia vida. De hecho, la historia narrada refleja la trayectoria de vida pero al mis- mo tiempo le atribuye significado, por lo cual encontramos semejanzas entre el desarrollo de la vida y el desarrollo de la narrativa o, como prefiere Georges Gusdorf, entre el estilo de la vida y el estilo de la obra.

Para este autor, que analiza específicamente las autobiografias, el estilo debe ser entendido no solamente como una regla de escritura sino como una línea de la vida.

La verdad de la vida no es distinta, específicamente, de la verdad de la obra. Hay un estilo de vida romántico, como hay un clásico, barroco, existencial o decadente. La vida, la obra, la autobiografía, se nos aparecen como tres aspectos de una misma afirmación, unidos por una constante imbricación.

Así, el privilegio de la autobiografía y de la historia de vida consiste en que nos muestran no las etapas de un desarrollo, cuyo inventario es tarea del historiador, sino el esfuerzo de un creador para dotar de sentido a su propia leyenda.

Surge de estas consideraciones la necesidad para el oralista de abordar la documentación oral en su complejidad, jamás desvinculando la identidad, la trayectoria de vida y la historia narrada. En este sentido nos apoya el semiólogo Roland Barthes, para quien se debe considerar en todo sistema semiológico,

no solamente dos sino tres términos distintos, pues lo que se aprehende no es un término después del otro, sino la correlación que los une: tenemos así el significante, el significado y el signo, que es el total asociativo de los dos primeros términos. 
Entonces, la entrevista como signo de una vida, de una identidad, debe ser analizada en el complejo historia narrada-trayectoria vivida. Considerar la historia de vida aisladamente la despoja de su valor: el significante es vacío, sólo el signo pleno está dotado de sentido.

Con el objetivo de reconocer los signos de identidad que caracterizan al narrador, para mejor interpretar la documentación creada, algunas conductas vienen siendo adoptadas por oralistas de diversas partes del mundo. Cuando se aplican correctamente estas conductas, el investigador puede dar cuenta de la información factual al mismo tiempo que interpreta la narrativa.

Los siguientes son algunos de los muchos pasos que el oralista puede dar para hacer un análisis global de la historia de vida: 1) reconocer los ejes temáticos predominantes, y el tono vital; 2) verificar la adecuación de la historia de vida a estereotipos narrativos; 3) develar la articulación de la narrativa en su ritmo; 4) reconocer y analizar los signos lingüísticos caracterizadores del medio y de la personalidad; 5) interpretar elementos dados por la observación participante, tales como ambiente, rasgos físicos o psicológicos de la personalidad, presencia de terceros u otras interferencias.

La lista de estos pasos es extensa y parece no tener fin ya que depende del límite al que llegue el empuje del investigador. El objetivo final será siempre establecer una relación entre la historia de vida, la identidad y la trayectoria de vida, elementos que se entrelazan de las formas más inesperadas, pero siempre en dos direcciones.

Lo importante es destacar que, sin despreciar la validez de la información de las entrevistas, el gran interés de la historia oral está en el análisis de la narrativa en cuanto construcción verbal subjetiva y consciente, expresando el sentido que el narrrador tiene de sí mismo en la historia.

Este enfoque no quiere menospreciar el impulso inicial de la historia oral: la búsqueda de la experiencia directa, del testimonio de la primera persona, que puede llenar los espacios vacíos dejados por los documentos tradicionales. Este impulso es fuente de una tensión moral y política que torna la historia oral atractiva, siendo usada por muchos como un medio de acción política y social, transformando los objetivos de la historia.

Mientras buscamos informaciones objetivas, poco modificaremos el contenido y el propósito de la historia. Éstos, de hecho, sólo cambiarán cuando pasemos a interesarnos por la subjetividad y la identidad de los narradores; por las formas culturales y procesos a través de los cuales los individuos expresan el sentido de sí mismos en la historia; en fin, por la "objetividad" de la subjetividad, si podemos hablar así. Esta tendencia, aunque reciente, parece que está trayendo más vida a la historia oral, encarando al sujeto en función de su interior y no de los hechos que le son externos. 